\title{
Experimental Results of Variable Frequency Drive for Three Phase Induction Motor Using Microcontroller
}

\author{
Hemish R. Choksi ${ }^{1}$, Hemant I. Joshi ${ }^{2}$ \\ Lecturer, Department of Electrical Engineering, Government Polytechnic, Himatnagar, India ${ }^{1}$ \\ Lecturer, Department of Electrical Engineering, Government Polytechnic, Ahmedabad, India ${ }^{2}$
}

\begin{abstract}
Induction motor for many years has been regarded as the workhorse in industrial applications. An induction motor can run only at its rated speed when it is connected directly to the main supply. However many application need variable speed operations. With the invention of variable voltage variable frequency drives (VVVF), the use of an induction motor has increased. Variable voltage variable frequency control provides a simple and cost efficient method for open-loop speed control of three phase induction motor. This technique is popularly known as V/f control. In this paper principle and operation of $\mathrm{V} / \mathrm{f}$ drive is summarized. This paper include experimental results of Voltage, Current and Speed on different frequencies which shows that induction motor speed is vary according to frequency input and simultaneously supply voltage is controlled to maintain V/f ratio constant.
\end{abstract}

Keywords: Induction motor, PWM, V/f Control, Duty Cycle Variation

\section{INTRODUCTION}

Over the past decade the field of power electronics has kept constant throughout the speed range. This is exactly passed through rapid development due to the advancement what V/f control tries to achieve.

of many modern technologies such as Microcontroller, DSP. The aforementioned technologies made power electronics projects and applications easier to implement and more accessible.

The complete system consist of two sections; a Power Circuit and a Control Circuit. The power circuit consists of the Three Phase Bridge Rectifier, C Filter and Three Phase PWM Inverter. On the other hand, the control circuit consists of the Micro controller, Opto couplers and Gate Drivers. An AC voltage input that is fed to a three phase diode bridge rectifier to produce DC output voltages which across a $\mathrm{C}$ filter will feed the three phase PWM inverter. The PWM inverter is controlled by a three phase PWM signal generated by a control circuit. The PWM inverter will then convert the DC voltage at the input to AC output voltage. The AC output voltage can be controlled in both magnitude and frequency (V/f constant). This control of voltage and frequency is required as it permits the user control the speed of an induction motor at different rates[4,10].

\section{VVVF CONTROL - PRINCIPLE OF OPERATION}

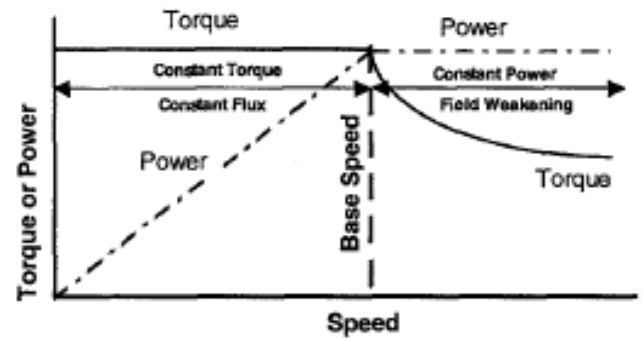

Fig.1 Torque-speed characteristics of the induction motor with V/f control.

AC Induction motors can operate in a "Constant Flux" or "Field Weakened" mode. The Constant flux mode is often referred to as the Constant Torque range and the Field Weakened mode as the Constant Power range[1,2].

\section{BASIC BLOCK DIAGRAM OF VVVF DRIVE- OPEN LOOP CONTROL}

Most modern VVVF drives operation requires the three basic sections as shown in Fig. 2, the rectifier, dc bus, and inverter. Converting a three-phase voltage source to DC using rectifier. After the power flows through the rectifiers it is stored on a dc bus. The dc bus contains

We will mention here only the salient points of $\mathrm{V} / \mathrm{f}$ control. The base speed of the induction motor is directly proportional to the supply frequency and the number of poles of the motor. Since the number of poles is fixed by design, the best way to vary the speed of the induction motor is by varying the supply frequency. The torque developed by the induction motor is directly proportional to the ratio of the applied voltage and the frequency of supply. By varying the voltage and the frequency, but keeping V/f ratio constant, the torque developed can be later deliver that power through the inverter section. The inverter contains transistors that deliver power to the motor. The "Insulated Gate Bipolar Transistor" (IGBT) is a common choice in modern V/f drives. The IGBT can switch on and off several thousand times per second and precisely control the power delivered to the motor. The IGBT uses "pulse width modulation" (PWM) technique to simulate a sine wave current at the desired frequency to the motor [3]. 


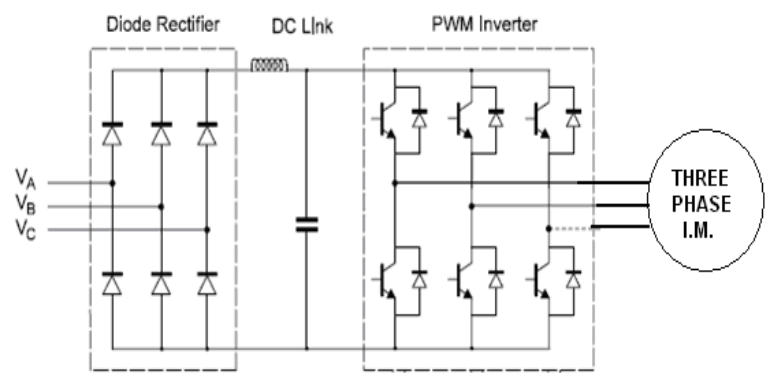

Fig.2 Block Diagram of VVVF Open Loop Control System.

\section{MODULATION TECHNIQUE FOR SPWM PATTERN GENERATION}

Sinusoidal Pulse-width modulation (PWM) is the technique of using switching devices to produce the effect of a continuously varying analogue signal; this PWM conversion generally has very high electrical efficiency. In controlling three-phase induction motor it is desirable to create three perfectly sinusoidal current waveforms in the motor windings, with relative phase displacements of $120^{\circ}$. When two switches are turned on alternately for equal times, then the voltage waveform across the load is zero. This mean that when the duty ratio is $50 \%$ the voltage on the average is 0 . When the duty ratio is $100 \%$ the voltage on the average is the maximum. The mean voltage varies with the duty ratio [5]. The waveform of the resultant load current depends on the impedance of the load $\mathrm{Z}$. If $\mathrm{Z}$ is mainly resistive, then the waveform of the current will closely follow that of the modulated square wave. If, however, $\mathrm{Z}$ is largely inductive, as with a motor winding or a filter choke, then the switching square wave waveform that depends mainly on the modulation of the duty ratio. If the duty ratio is varied sinusoidally in time, then the current in an inductive load has the form of a sine wave at the modulation frequency, lagging in phase. The amplitude of the voltage can be adjusted by controlling the depth of modulation, that is, the deviation of the duty ratio from 50\%. For example, a sine wave PWM signal which varies from $5 \%$ to $95 \%$, giving $90 \%$ modulation, will produce a voltage nine times greater than that produced by a signal which varies only from $45 \%$ to $55 \%$, giving only $10 \%$ modulation. For three-phase a.c. motor control, three such waveforms are required, necessitating three pairs of switches connected in a three-phase bridge.

The inductance required to integrate the waveform can usually be provided by the inductance of the stator windings of the motor. The modulations in the three switching waveforms must be maintained at a constant relative phase difference of $120^{\circ}$, so as to maintain motor current sine waves which are themselves at a constant $120^{\circ}$ phase difference. The modulation depth must be varied with the modulation frequency so as to keep the magnetic flux in the motor at approximately the design level. In practice, the frequency of the modulation is usually between zero and $50 \mathrm{~Hz}$. The switching frequency depends on the type of power device that is to be used. The waveform can be stored as a look-up table of numbers representing the sine wave. To generate the three phases, this table can be read at three points that have the correct $120^{\circ}$ phase relationship. The numbers taken from the table represent the duty ratios corresponding to $100 \%$ modulation, these numbers can then be scaled down by multiplication or some equivalent technique to give the correct duty-ratio numbers for the modulation depth required. Information to determine the modulation depth is derived from the frequency input. By applying digital multiplication processes to internal look-up table values, the microcontroller calculates the on-time for each of the six power switches, and this process is repeated at regular intervals of time[6,8].

\section{MOTOR CONTROL}

Controlling an a.c. induction motor by the technique of sine wave-weighted pulse width modulation (PWM) switching gives the benefits of smooth torque at low speeds and also complete speed control from zero up to the nominal rated speed of the motor. To derive a varying ac voltage from power inverter PWM is required to control the duration of switches ON and OFF times. Three PWMs are required to control the upper three switches of the power inverter.

The lower three switches are controlled by inverted PWM signals of the corresponding upper switch. A dead time is given between switching off the upper switch and switching on the lower switch and vice versa, to avoid shorting the DC bus. Microcontroller AT89C52 and PIC16F84 is used for PWM generation [7,9].

\section{GENERATION OF DUTY RATIO VARIATION AT DIFFERENT FREQUENCIES}

The sample data of sinusoidal waveform is calculated and stored in the look up table. Sinusoidal wave is divided into 72 samples. In a sampling interval 72 every equivalent area of the wave has some duty ratio. This duty ratio is vary sinusoidally. The value read from sine table is scaled based on the motor frequency input and value reaches $90^{\circ}$.

For $20 \mathrm{~Hz}$ motor input frequency duty cycle variation is from $50 \%$ to $60 \%$. Similiarly for $25 \mathrm{~Hz}$ frequency duty cycle variation is from $50 \%$ to $63 \%$ and for $50 \mathrm{~Hz}$ frequency duty cycle variation is from $50 \%$ to $77 \%$ which shown in fig 3,4. The depth of modulation increases as input frequency increases[6,8].

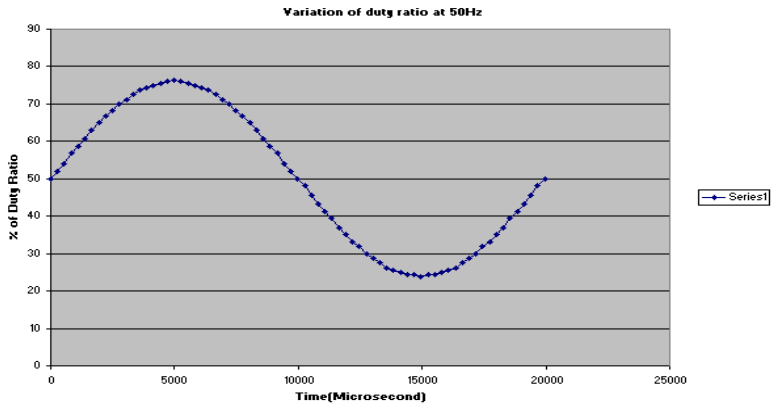

Fig.3 Variation of duty ratio at $50 \mathrm{~Hz}$ Frequency 
INTERNATIONAL JOURNAL OFINNOVATIVE RESEARCH IN ELECTRICAL, ELECTRONICS, INSTRUMENTATION AND CONTROL ENGINEERING Vol. 3, Issue 3, March 2015

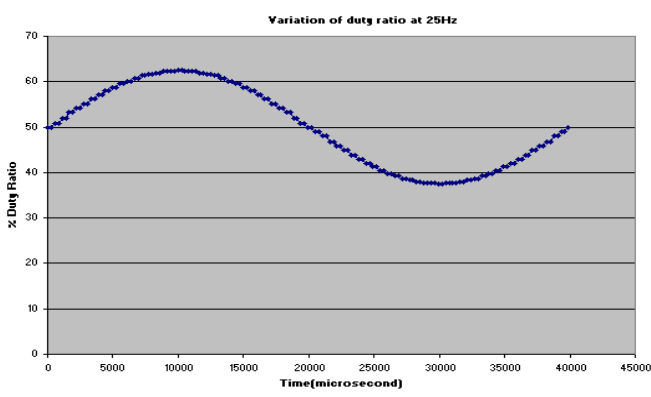

Fig.4 Variation of duty ratio at $25 \mathrm{~Hz}$ Frequency

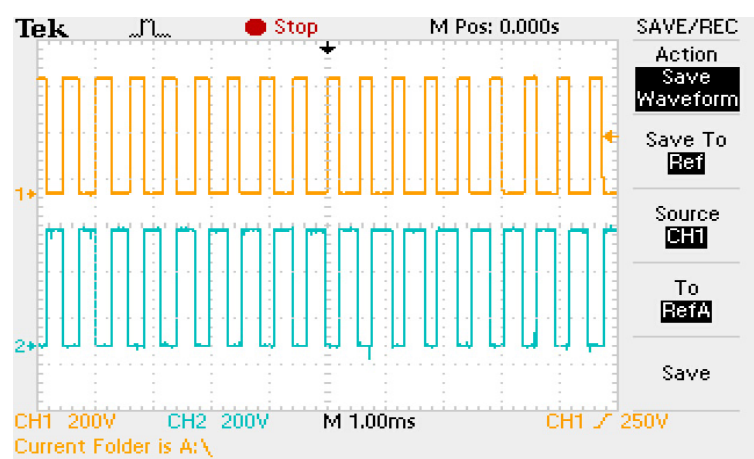

Fig.5 Variation of Duty Cycle at $25 \mathrm{~Hz}$

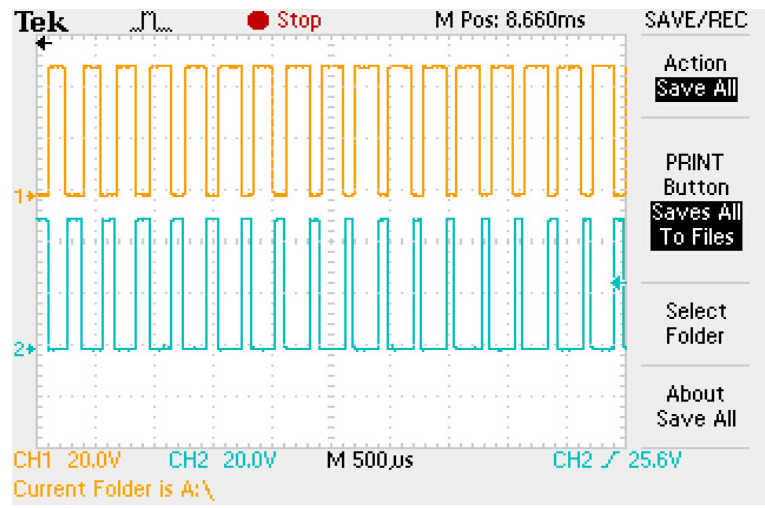

Fig.6 Variation of Duty Cycle at $50 \mathrm{~Hz}$

The amplitude of voltage is determined by depth of modulation of PWM signal. Variation of duty cycle shows that depth of modulation increases with input frequency.

Maximum duty cycle available when the sine value reaches $90^{\circ}$.

\section{EXPERIMENTAL RESULTS}

Performance test and results of 3-Phase, 1 H.P, Open-loop control Variable frequency drive are conducted on a motor with the following specifications:

Terminal Voltage $=415 \mathrm{~V}$

Frequency $=50 \mathrm{~Hz}$

Horsepower $=1 / 4 \mathrm{HP}$

Speed $=1440$ RPM

Rated Current $=0.6 \mathrm{~A}$

Test Condition $=$ no load

To achieve smooth speed change the fundamental frequency is varied at small steps. The drive is tested for $20 \mathrm{~Hz}$ to rated frequency.
TABLE I : Operation of Three Phase Induction Motor with V/f Drive

\begin{tabular}{|c|c|c|c|c|c|}
\hline Test & $\begin{array}{c}\text { Set } \\
\text { Frequency } \\
(\mathrm{Hz})\end{array}$ & $\begin{array}{c}\text { Actual } \\
\text { Speed } \\
(\mathrm{RPM})\end{array}$ & $\begin{array}{c}\text { Line } \\
\text { Voltage } \\
(\mathrm{V})\end{array}$ & $\begin{array}{c}\text { Line } \\
\text { Current } \\
(\mathrm{A})\end{array}$ & $\begin{array}{c}\text { V/f } \\
\text { Ratio }\end{array}$ \\
\hline 1 & 20 & 568 & 164 & 0.14 & 8.2 \\
\hline 2 & 25 & 712 & 203 & 0.16 & 8.12 \\
\hline 3 & 30 & 856 & 244 & 0.17 & 8.13 \\
\hline 4 & 35 & 1002 & 277 & 0.19 & 7.91 \\
\hline 5 & 40 & 1136 & 319 & 0.21 & 7.98 \\
\hline 6 & 45 & 1272 & 357 & 0.22 & 7.93 \\
\hline 7 & 50 & 1428 & 396 & 0.23 & 7.92 \\
\hline
\end{tabular}
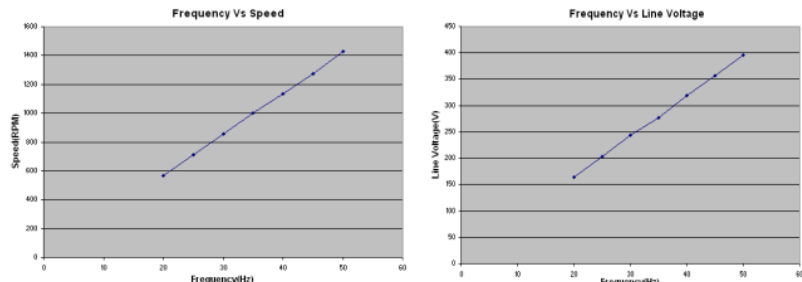

Fig.7 Speed, Line voltage and Set Frequency

A. $\quad$ Motor Line Current $I_{R}, I_{Y}$ at $50 \mathrm{~Hz}$ and $20 \mathrm{~Hz}$

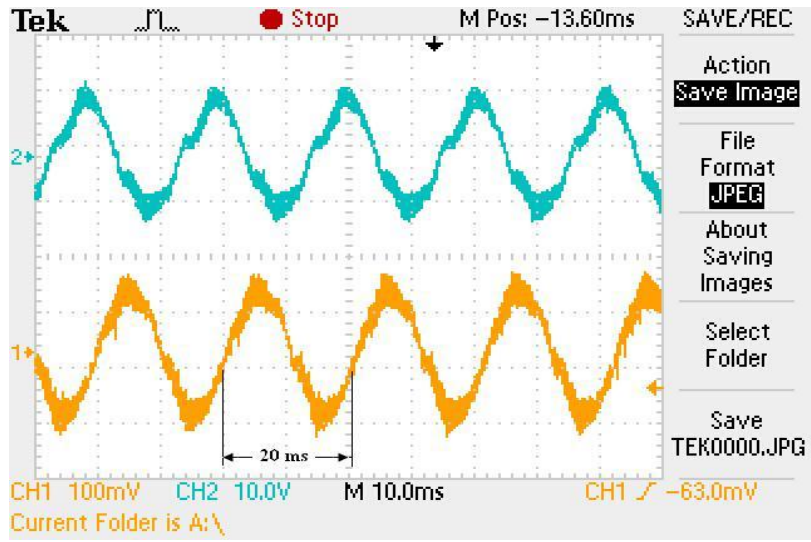

Fig.8 Motor Line Current IR, IY at $50 \mathrm{~Hz}$ $\mathrm{Y}-\mathrm{Scale}=0.25 \mathrm{~A} / \mathrm{Div}, \mathrm{X}-\mathrm{Scale}=10 \mathrm{msec} / \mathrm{Div}$

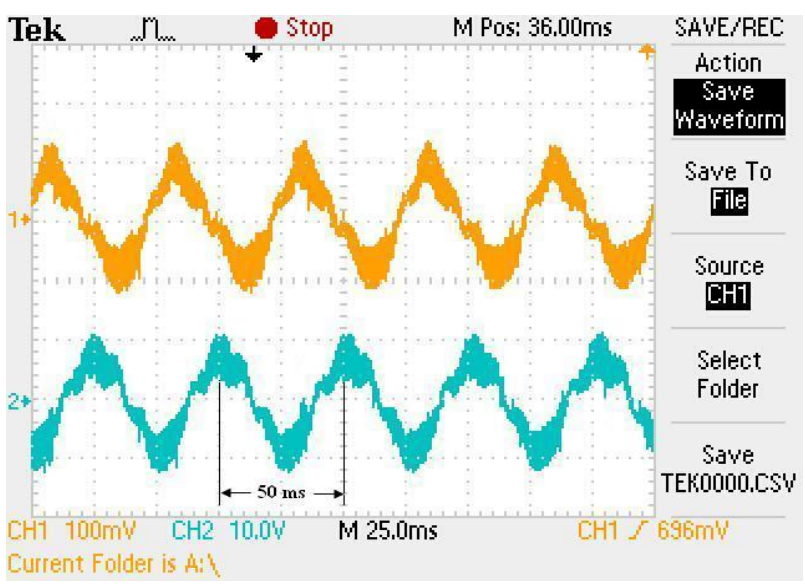

Fig.9 Motor Line Current IR, IY at $20 \mathrm{~Hz}$ $\mathrm{Y}-\mathrm{Scale}=0.25 \mathrm{~A} / \mathrm{Div}, \mathrm{X}-\mathrm{Scale}=10 \mathrm{msec} / \mathrm{Div}$ 
B. at $50 \mathrm{~Hz}$
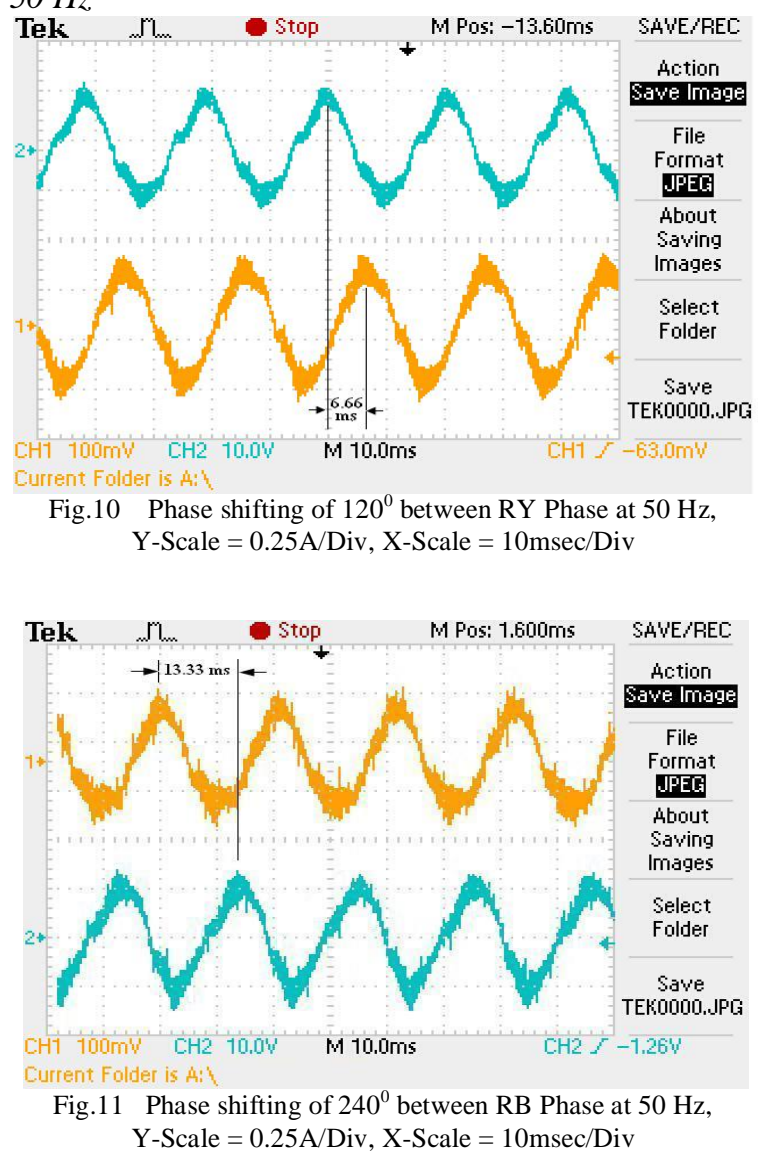

C. Motor Line Voltage $V_{R Y}$ at $50 \mathrm{~Hz} \& 20 \mathrm{~Hz}$ Operation

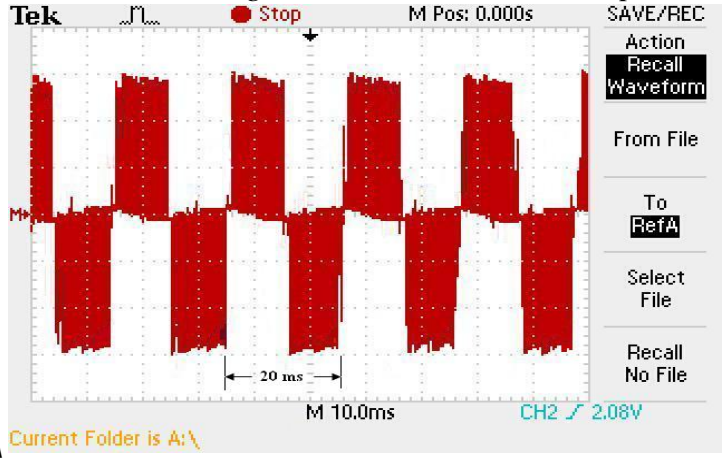

Fig.12 Motor Line Voltage $\mathrm{V}_{\mathrm{RY}}$ at $50 \mathrm{~Hz}$, Y-Scale $=200 \mathrm{~V} / \mathrm{Div}, \mathrm{X}$-Scale $=10 \mathrm{msec} / \mathrm{Div}$

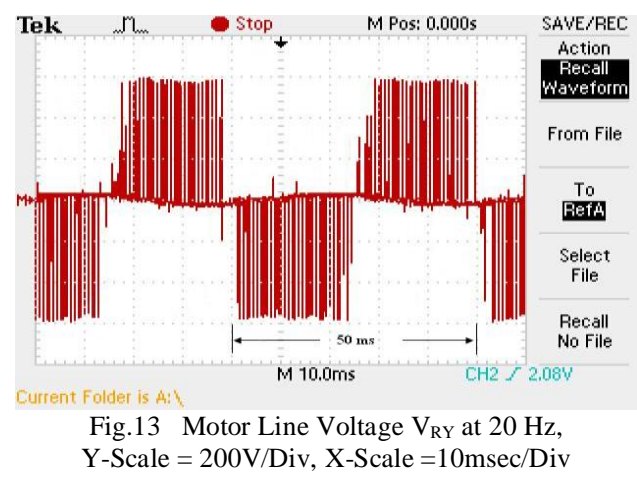

$D$. Speed and line Current $I_{R}$ of 3-Phase Induction Motor

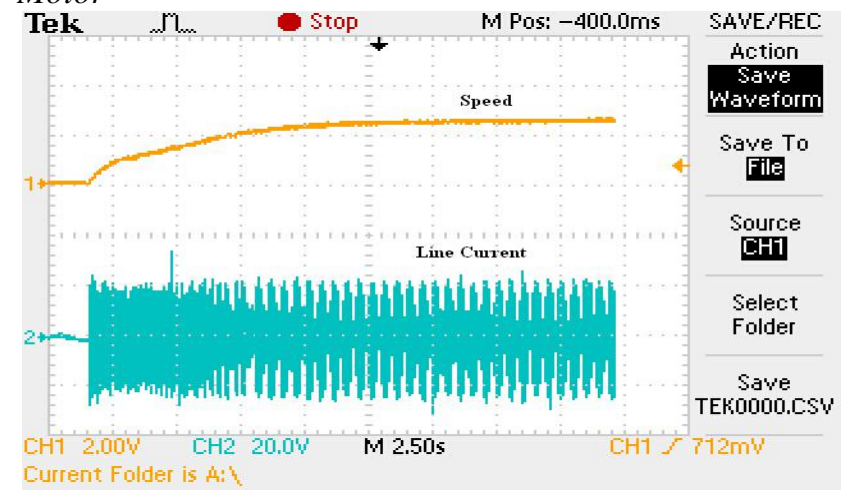

Fig.14 Speed and line Current $I_{R}$ of 3-Phase Induction Motor

Results show that line current and line voltage frequency is vary according to input frequency and rms value of line voltage increases with input frequency and maintain V/f ratio constant. Line current is nearly sinusoidal. Motor speed increases with increase of input frequency.

\section{CONCLUSION}

A fully functional simple and low-cost Variable Frequency Drive is implemented with low cost circuits and components and have control over motor up to rated speed. Experimental results of Voltage, Current and Speed for different frequencies has been summarized which shows that induction motor speed is vary according to frequency input and simultaneously supply voltage is controlled to maintain V/f ratio constant. Thus torque developed by motor will remain constant throughout the speed range. Voltage waveform is symmetric and current is found to be nearly sinusoidal. Phase shifting is provided between two phases.

\section{ACKNOWLEDGMENT}

The authors acknowledge gratefully the support provided by Department of Electrical Engineering, Nirma University, KOLORROL Energy Pvt. Ltd. and all individuals who are directly or indirectly involved in this work.

\section{REFERENCES}

[1]. Malcon Barnes, "Practical Variable Speed Drives and Power Electronics", Newnes : Burlington 2003.

[2]. Muhammad H. Rashid, "Power Electronics circuits, devices, and applications", 3rd addition, Prentice- Hall of India Private limited, New Delhi - 2007.

[3]. B. Biswas, S. Das, P. Purkait, M. S. Mandal and D. Mitra "Current Harmonics Analysis of Inverter-Fed Induction Motor Drive System under Fault Conditions", Proceedings of the International MultiConference of Engineers and Computer Scientists 2009 Vol II IMECS 2009, March 18 - 20, 2009, Hong Kong.

[4]. Omar M F Muhaildin, Takyin Chan, The Design and Implementation of a Three Phase Power Converter in the Power Electronics and Drives Subject, School of Electrical Engineering Victoria University PO Box 14428 MC, Melbourne VIC 8001, Australia.

[5]. Weixing Lin, A New Approach to the Harmonic Analysis of SPWM Waves, IEEE2006 Proceedings, International Conference on Mechatronics and Automation, 25-28 June 2006, pp. 390 - 394.

[6]. Application Note, Power semiconductor Applications, Philips Semiconductors.

[7]. Application Note AN889, VF Control of Three Phase Induction Motors Using PIC16F7X7, Microchip.

[8]. M. Irfan Anis, Naveed Ahmed, Muhammad Tahir Qadri and Mubeen Sirhindi, Techniques for SPWM using LUTs on low-cost 
microcontrollers, International Colloquium on Signal Processing and Its Applications, 6-8 March 2009, Page(s):327 - 331.

[9]. Hemish Choksi, D.B.Dave, Amar Hinduja, "Development of Variable Voltage Variable Frequency Drive for Three Phase Induction Motor" A National Level Technical Symposium, U.V.Patel College of Engineering, Ganapat University, Mahesana, 12th to 13th Mar. 2010,pp. 82-83.

[10]. Hemish Choksi, D.B.Dave, Amar Hinduja, "Simulation of Variable Voltage Variable Frequency Drive for Three Phase Induction Motor using SPWM Technique", 4th National Conference on Current Trends in Technology (NUCONE 2009), Nirma University, Ahmedabad, 25th to 27th Nov. 2009, section IV, pp.81 to 84 